\title{
Importance of cardio-oncology. How to detect subclinical heart failure
}

\author{
Importancia de la cardiooncología. Cómo detectar la insuficiencia cardiaca subclínica \\ Jesús De Rubens-Figueroa ${ }^{1 *}$ and Rocío Cárdenas-Cardós ${ }^{2}$ \\ ${ }^{1}$ Cardiology Department, Echocardiography Laboratory; ${ }^{2}$ Oncology Department. Instituto Nacional de Pediatría, Mexico City, Mexico
}

\begin{abstract}
Today one of the main causes of mortality is cancer. Survival in cancer patients has increased from 1970 (25\%) to the present (80\%). Following the introduction of anthracyclines as a cancer treatment since $1960-70$, more than $60 \%$ of patients are treated with these agents, although chemotherapeutic exposure leads to cardiovascular diseases as the main cause of mortality in surviving patients. of cancer in the s. XXI. There are multiple factors that increase the sensitivity of anthracyclic-induced cardiotoxicity. In 1970 the gold standard for the detection of ventricular dysfunction was endomyocardial biopsy, subsequently the detection and management of cardiotoxicity was guided by symptoms, in 1981 the detection of cardiotoxicity was reported with the determination of the ejection fraction of the left ventricle (LVEF), by 2D echocardiography. Currently, the 3D echocardiogram for LVEF and systolic and diastolic volumes have presented a high correlation of the values obtained by magnetic resonance imaging for the evaluation of cardiac function. Today strain, strain-rate and speckle tracking echocardiography are used to determine regional and global myocardial function. For a comprehensive assessment, these results can be complemented with cardiac biomarkers (troponins) and electrocardiographic changes. In this way, subclinical heart failure can be detected and timely treatment can be given.
\end{abstract}

Key words: Cardiotoxicity. Cáncer. Strain. Heart failure. Chemotherapy.

\section{Resumen}

Hoy una de las principales causas de mortalidad es el cáncer. La supervivencia en pacientes con cáncer ha incrementado de 1970 (25\%) a la actualidad (80\%). A raíz de la introducción de las antraciclinas como tratamiento de cáncer desde 19601970, más del 60\% de los pacientes son tratados con estos agentes; sin embargo, la exposición de quimioterápicos conlleva las enfermedades cardiovasculares como la principal causa de mortalidad en enfermos supervivientes de cáncer en el s. XXI. Hay múltiples factores que incrementan la sensibilidad de cardiotoxicidad inducida por antracíclicos. En 1970 el estándar de oro para la detección de disfunción ventricular era la biopsia endomiocárdica, en forma posterior la detección y manejo de la cardiotoxicidad fue guiada por los síntomas, en 1981 la detección de cardiotoxicidad fue reportada con la determinación de la fracción de expulsión del ventrículo izquierdo (FEVI) por ecocardiografía 2D. En la actualidad el ecocardiograma 3D para FEVI y volúmenes sistólico y diastólico han presentado una alta correlación de los valores obtenidos por resonancia magnética para la evaluación de la función cardiaca. Hoy en día la ecocardiografía strain, strain-rate y speckle tracking se utilizan para determinar la función miocárdica regional y global. Para una valoración integral estos resultados

\section{Correspondencia:}

*Jesús De Rubens-Figueroa

E-mail: derubens @ hotmail.com
Date of reception: 11-12-2019

Date of acceptance: 07-02-2021

DOI: 10.24875/ACME.M21000201
Available online: 19-07-2021

Arch Cardiol Mex (Eng). 2021;91(2):197-202

www.archivoscardiologia.com 2604-7063 / @ 2021 Instituto Nacional de Cardiología Ignacio Chávez. Published by Permanyer. This is an open access article under the CC BY-NC-ND license (http://creativecommons.org/licenses/by-nc-nd/4.0/). 
se pueden complementar con biomarcadores cardiacos (troponinas y propéptido natriurético tipo B) y cambios electrocardiográficos. De esta forma se puede detectar insuficiencia cardiaca subclínica y dar un tratamiento oportuno.

Palabras clave: Cardiotoxicidad. Cáncer. Strain. Insuficiencia cardiaca. Quimioterapia.

\section{Introduction}

Today, one of the main causes of mortality is cancer. Survival in cancer patients has increased from $1970(25 \%)$ to current day (80\%), due to prevention, early diagnosis and timely treatment ${ }^{1}$; however, cancer treatment entails medium- and long-term complications, with the main one being premature cardiovascular disease, due to exposure to chemotherapeutic drugs such as anthracyclines ${ }^{2}$. Therefore, cardiovascular disease is the leading cause of mortality in cancer survivors $^{3}$. Mortality from cardiovascular conditions is 3.4 times higher than that expected in the general population 4 .

Following the introduction of anthracyclines as cancer treatment since $1960-1970$, more than $60 \%$ of cancer patients are treated with these agents; however, many of them have been associated with ventricular dysfunction, cardiomyopathy, QT-interval prolongation, valve insufficiency, myocardial ischemia, pericarditis, arrhythmia, syncope, coronary artery disease and sudden death ${ }^{1,5-7}$

Myocardial involvement with regard to the time of anthracycline treatment initiation has been divided into: acute (first administration week), early or subacute (from one week to one year) and chronic (longer than one-year administration), and $10 \%$ of patients with heart failure have been detected even up to 20 years after having started treatment ${ }^{8-10}$.

It is important for risk factors to be detected, which include: some polymorphisms, obesity, arterial hypertension, age younger than four years, female gender, metabolic syndrome, radiotherapy higher than $5 \mathrm{~Gy}$, monoclonal antibodies, hematopoietic cell transplantation, mitoxantrone, 5-fluoroacil, alkylating agents such as cyclophosphamide, cisplatin, biological agents such as trastuzumab and rituximab, and tyrosine kinase inhibitors such as imatinib, sunitinib and dazatinib ${ }^{8-11}$. The factor that entails the highest risk in statistical analyses is anthracycline cumulative dose $\geq 300 \mathrm{mg} / \mathrm{m}^{2}$, with an incidence of up to $14.6 \%$.

The cardiotoxicity mechanism elicited by anthracyclines consists of a release of free radicals and peroxides that damage the cardiac fiber, inhibit the synthesis of proteins, with induction of the apoptotic cascade and cell death ${ }^{10,12}$. Anthracyclines inhibit DNA and RNA synthesis, causing filament rupture with mutagenic and carcinogenic effect, formation and deposit of ferric iron in cardiomyocytes, thus decreasing the quinone group, forming superoxide radicals and hydrogen peroxide, which damage mitochondrial membrane integrity, inhibit the entry of intracellular calcium and sodium ions, necrosis and apoptosis, thus decreasing myocardial contractility, causing cardiac fibrosis, heart failure and dilated and/or restrictive cardiomyopathy ${ }^{13-17}$. On the other hand, anthracyclines increase the levels of pro-inflammatory cytokines, given that they induce the release of histamine, tumor necrosis factor alpha and interleukin 2, which cause dilated cardiomyopathy and beta-adrenergic dysfunction ${ }^{15}$.

The first cardiotoxicity report was carried out in New York in $1967^{18}$. In 1970, the gold standard for the detection of ventricular dysfunction was endomyocardial biopsy; today, this invasive possibility has been discarded, especially in children, thanks to technological advances in cardiotoxicity-detection methods ${ }^{10}$.

In 1980, cardiotoxicity detection and management was guided by symptoms and it was complicated, since there are symptoms that are similar for heart failure and cancer, such as dyspnea, fatigue, peripheral edema, etc. In 1981, cardiotoxicity detection was reported with left ventricular ejection fraction (LVEF) determination by 2D echocardiography. In 2000, LVEF limitations were reported, as an imperfect marker, given that it is insensitive to early changes in heart dysfunction, with known limitations, where deterioration occurs at late stages of the disease $\mathrm{e}^{19,20}$.

Three-dimensional (3D) echocardiogram has shown a high correlation for the evaluation of heart LVEF function and systolic and diastolic volumes with magnetic resonance imaging (MRI)-obtained values ( $r$ : 0.96, $r$ : 0.97 and $r: 0.93$, respectively). As for LVEF, it is considered abnormal when it is below $5 \%$ of the normal value of $53 \%$, or $10 \%$ below baseline LVEF in asymptomatic patients ${ }^{21,22}$.

There are current studies where left ventricular involvement has been adequately studied; however, few studies show that anthracyclines can affect right ventricular function as well, a concept that has not yet been adequately explored ${ }^{23}$.

Today, advances in cardiac imaging, especially in non-invasive techniques, are highly useful, such as 
strain (myocardial deformation) and strain-rate (deformation velocity) echocardiography. Measurement of both for regional and global myocardial function using $2 \mathrm{D}$ strain echocardiography is known as speckle tracking. These echocardiographic techniques measure the deformation and motion existing in cardiac contraction, which has several types or directions: longitudinal (base-apex), circumferential and radial. It should also be noted that myocardial fibers also have torsional and rotational mechanisms ${ }^{8,24,25}$, which will be studied more closely in the coming years.

The strain (myocardial deformation)/strain-rate (shortening speed) image is the measurement of the myocardial fiber movement rates, at its displacement in translation/rotation movements, measured in radial/longitudinal directions gradient and that can be measured on different myocardial segments. This is a highly useful method for recognizing deficiency in myocardial fiber deformation and shortening prior to its clinical manifestation as heart failure ${ }^{26}$.

Strain is the percentage of fiber size change corrected by its original size, which is expressed with the following formula: Strain $=(\mathrm{L} 1-\mathrm{L} 0 / \mathrm{L} 0)$, where L1 is equal to the length of the fiber at its maximum contraction and LO is its length at rest. The strain value is expressed as a percentage of change in size, and can be positive or negative depending on whether the displacement approaches or moves away from the reference point ${ }^{26}$.

On the other hand, the strain-rate value is obtained from the knowledge of a fiber basal length (LO) and initial and final velocity (V0, V1) at which the fiber is deformed. The velocity change between the two points can be calculated and corrected, by the length of the fiber with the following formula: (VO-V1)/LO26.

Cardiac strain and strain-rate measurement, which assesses myocardial fiber displacement with the speckle-tracking technique throughout the cardiac cycle, can be carried out by tissue Doppler or 2D speckle-tracking echocardiogram and thus detect different myocardial segments (speckle tracking) with different depth characteristics (frame-rate) (40-90 frames/s or $\geq 40 \%$ of cardiac function) on the different studied segments, during that cardiac cycle, either in systole or diastole and, simultaneously, global strain of all 18 cardiac segments will be reported ${ }^{22}$.

Longitudinal and/or radial strain decrease in patients undergoing chemotherapy are early and highly-sensitive indicators of anthracycline myocardial toxicity.

As for diastolic function, echocardiographic parameters (trans-mitral $\mathrm{E} / \mathrm{A}$, isovolumetric relaxation times prolongation) have been reported to precede LVEF significant decreases, which appears to correspond to an early sign of left ventricular dysfunction in chemotherapy-treated patients ${ }^{22}$.

Global longitudinal strain (GLS) normal parameters in boys are generally considered to be $-19.4 \%(-20.4$ to $-18.9 \%)$ and, in girls, $-20.5 \pm 2.2^{22}$; between -16 and $-18 \%$ are intermediate and $<16 \%$ abnormal $^{19,23}$ (Table 1). Importantly, having baseline echocardiographic determinations (pre-chemotherapy) is recommended, taken as left ventricle strain Z-score reference values for children, which will serve to compare with subsequent control measurements in a personalized way, since there are no precise normal universal values for children ${ }^{20,27}$. Echocardiographic follow-up varies according to each hospital center but, by consensus, a first control one month after the start of chemotherapy, and at three, six and twelve months for early assessment is recommended; in special cases, evaluation can be made earlier ${ }^{8}$.

A study carried out in 2012 found that, in patients with anthracycline administration, GLS was altered on first echocardiographic control, but LVEF was later decreased at 8-month control assesment ${ }^{28,29}$ (Fig. 1). It is also highly important for diastolic dysfunction to be determined, since it is the first manifestation of anthracycline-induced cardiotoxicity ${ }^{30}$.

For comprehensive assessment, these results can be complemented with cardiac biomarkers (troponins are said to detect cardiomyocyte injury and death and proB-type natriuretic peptide), which are recommended to be obtained on a baseline determination and subsequently during controls, for establishing a comparison with previous results; this provides us with inflammation data that are highly useful in patient evaluation, which, together with echocardiographic results, gives us a close idea of myocardial damage.

Electrocardiogram is also useful for monitoring arrhythmias caused by anthracycline administration, such as: long QT, ventricular and supraventricular tachycardia and third-degree (complete) atrioventricular block ${ }^{10,16}$.

As for strain parameters, a GLS reduction $>15 \%$, with a baseline parameter of $100 \%$, was suggested to be of subclinical importance, as well as a $10 \%$ decrease from baseline ejection fraction ${ }^{10,29}$ (Fig. 1).

The heart has a significant reserve, and the damage that alters systolic and diastolic function parameters becomes evident until cardiac reserve has been lost, and thus heart damage may not occur until years or 
Table 1. Normal control figures

\begin{tabular}{|l|r|r|r|}
\hline Age, years & Global longitudinal strain & Global circumferential strain & Global radial strain \\
\hline $1-4$ & $-20.7 \pm 1.30$ & $-20.0 \pm 0.34$ \\
\hline $5-9$ & $-21.0 \pm 1.30$ & $-20.9 \pm 2.00$ & \\
\hline $10-14$ & $-21.8 \pm 1.30$ & $-21.5 \pm 1.70$ & $38.6 \pm 14.2$ \\
\hline $15-19$ & $-22.5 \pm 1.30$ & $-21.9 \pm 2.10$ & \\
\hline
\end{tabular}
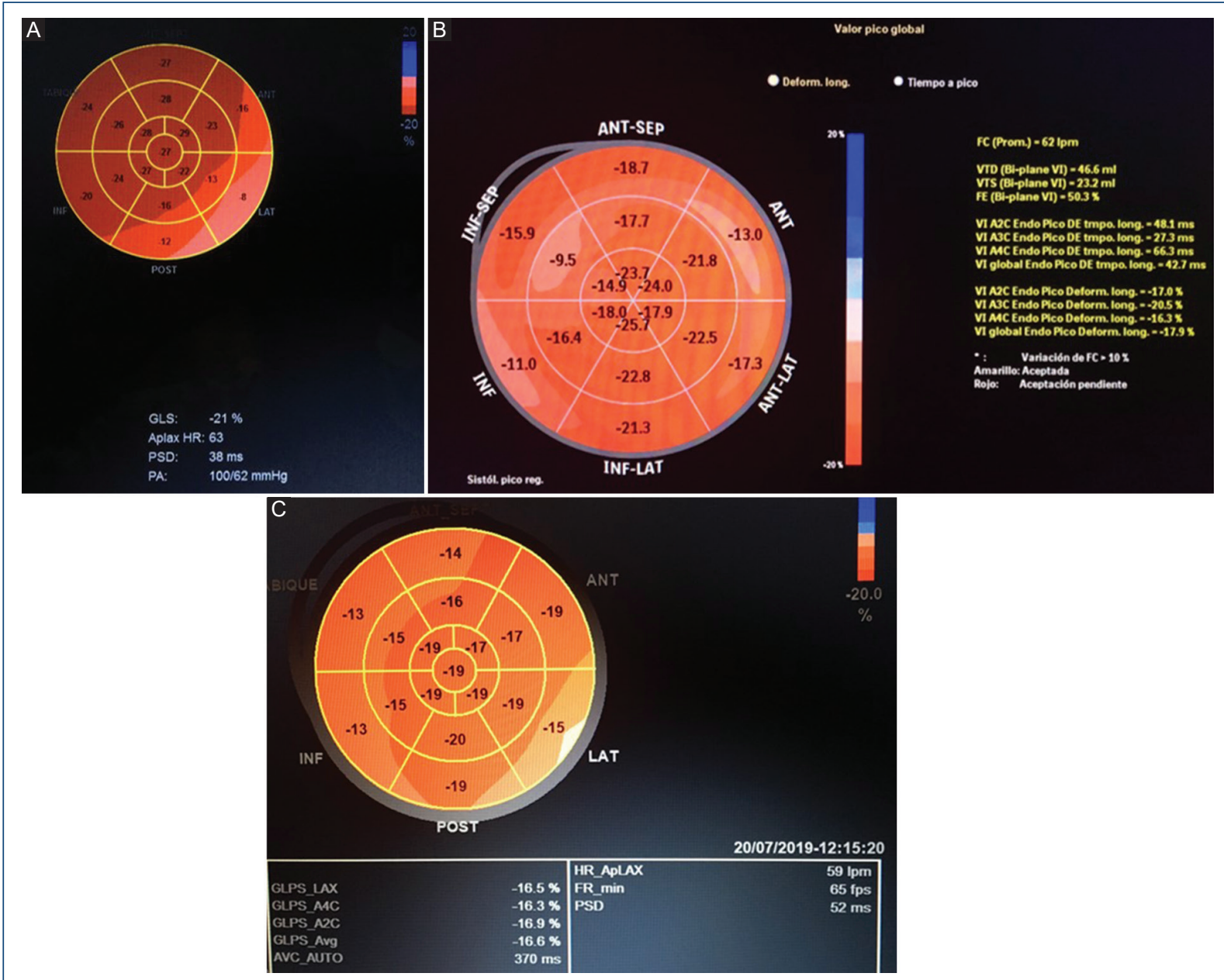

Figure 1. Three moments of myocardial fiber strain control evolution in a patient undergoing anthracycline administration. A: baseline measurement (prior to treatment): EF of $60 \%$ with GLS at $-21.0 \%$. B: six months later: EF of $50.3 \%$ with GLS at $-17.9 \%$. C: twelve months later, with EF of $49 \%$ and SGL of $-16.6 \%$.

EF: ejection fraction; GLS: global longitudinal strain.

decades after cardiotoxic treatment, and ventricular dysfunction has a mean survival of 7.1 years ${ }^{4,22,31}$.

Long-term follow-up should probably be carried out 2,5 and 10 years after chemotherapy ${ }^{32}$.
As for diagnosis, MRI is useful for assessing ventricular function and is recommended when there is echocardiogram poor quality image, or when some other data and/or endocardial borders need to be specified. 
For subclinical damage-producing cardiotoxicity to be reduced, there are three options: a) decreasing anthracyclines concentration (not higher than a cumulative dose of $300 \mathrm{mg} / \mathrm{m}^{2}$ ); b) developing less cardiotoxic analogues (liposomal anthracyclines, daunorubicin), and c) administration of cardioprotective agents to prevent myocardial remodeling and progression to heart failure, such as dexrazoxane (iron chelating agent and oxygen free-radicals stimulant). And for treatment, we have diuretics, angiotensin-converting enzyme inhibitors such as enalapril, and beta-blockers such as carvedilol, statins, metoprolol and bisoprolol, vitamins A, E, C, coenzyme $Q$ and carnitine ${ }^{16,22,33,34}$. These options can recover more than $50 \%$ of LVEF, whereby $85 \%$ of patients survive, with heart rate being increased.

Recently, antibodies against HER2/Neu gene (ErbB2) have been mentioned as prophylactic treatment, since they reduce the risk of recurrence and death in HER2 gene-positive patients ${ }^{22}$.

Anthracycline-induced cardiomyopathy has been associated with a particularly unfavorable prognosis, with two-year mortality of up to $60 \%$.

Today, cardiotoxicity-associated mortality is $10 \%$ for some reviews, but it significantly increases with anthracycline cumulative doses 29,34 .

\section{Conclusions}

To decrease morbidity and mortality of cancer patients treated with chemotherapy, it is necessary to early and sub-clinically detect ventricular dysfunction with strain echocardiography. Therefore, any patient receiving potentially cardiotoxic chemotherapy should undergo a systematic clinical follow-up with biomarkers and echocardiography, in order to offer different treatment options that recover more than $50 \%$ of ventricular function and thus prevent heart failure.

\section{Funding}

This research has not received specific support from public or commercial sector agencies, or non-profit entities.

\section{Conflicts of interests}

The authors declare that they have no conflicts of interest.

\section{Ethical disclosures}

Protection of human and animal subjects. The authors declare that no experiments have been performed on humans or animals for this research.

Confidentiality of data. The authors declare that they have followed the protocols of their work center on the publication of patient data.

Right to privacy and informed consent. The authors declare that no patient data appear in this article.

\section{References}

1. Shankar SM, Marina N, Hudson MM, Hogdson DC, Adams J, Landier W, et al. Monitoring for cardiovascular disease in surviviors of childhood cancer: report from the cardiovascular disease Task Force of the children's oncology group. Pediatrics. 2008;121:387-96.

2. Rathe M, Torp C NL, Oxhoj H, Nielsen G. Long-term cardiac follow-up of children treated with anthracycline doses of $300 \mathrm{mg} / \mathrm{m}^{2}$ or less for acute lymphoblastic leukemia. Pediatr Blood Cancer. 2010;54:444-8.

3. Kucharska W, Negrusz-Kawecha M, Gromkowska M. Cardiotoxicity of oncological treatment in children. Adv Clin Exp Med. 2012;21:281-8.

4. Fidler MM, Reulen RC, Henson K, Kelly J, Cutter D, Levit GA, et al. Population-based long-term cardiac-specific mortality among 34489 five-year survivors of childhood cancer in Great Britain. Circulation. 2017;135:951-63.

5. Kremer LC, Caron HN. Anthracycline carwdiotoxicity in children. N Engl J Med. 2004;351:120-1.

6. Godishala A, Young S, Asnani A. Cardioprotection in the modern era of cancer chemotherapy. Cardiol Rev. 2018;26:113-21.

7. Armenian SH, Armstrong GT, Avne G, Chow EJ, Erhardt MJ, Ky B, et al. Cardiovascular disease in surviviors of childhood cancer. Insights into epidemiology, pathophysiology and prevention. J Clin Oncol. 2018;36:2135-44.

8. Plana JC, Galderisi M, Barac A, Ewer MS, Ky B, Scherrer CM. et al. Expert consensus for multimodality imaging evaluation of adult patients during and after cancer therapy: A report from the American Society of Echocardiography and the European Association of cardiovascular imaging. J Am Soc Echocardiogr. 2014;27:911-39.

9. González OA, Machín GS, Arencibia NA, Collazo AJ, Rivera KC, Bravo POL, et al. Evaluación ecocardiográfica longitudinal en pacientes con leucemia linfoide aguda que recibieron antracilinas durante la edad pediátrica. Rev Cub Hematol, Inmunol y Hemoter. 2016;32:470-82.

10. Asnani A, Neilan GT, Tripathy D, Scherrer CM. Clinical manifestations, monitoring and diagnosis of anthracycline-induce cardiotoxicity. Topic 2018.

11. Bini I, Asaftei DS, Riggi Ch, Tirtei E, Manicone R, Biasin E, et al. Anthracycline-induced cardiotoxicity in patients with paediatric bone sarcoma and soft tissue sarcoma. Cardiol Young. 2017;27(9):1815-22.

12. Cardenas CR. Mecanismos de cardiotoxicidad de la quimioterapia. Gac Mex Oncol. 2009;8:3-7.

13. Navarrete REM, Zapata T MM, Vizcaíno AA, Garduño EJ, Dorantes AE, Palomo C MA. El ecocardiograma y su papel en niños con cáncer. Bol Med Hosp Infant Mex. 2013;70:133-7.

14. Larussi D, Indolfi P, Casale F, Martino V, Di Tullio MJ, Calabró R. Anthracycline-induced cardiotoxicity in children with cancer: Strategies for prevention and management. Paediatr Drugs. 2005;7:67-76.

15. Hurtado NS, Mejía CAM, Sanabria CHA. Cardiotoxicidad por quimioterapia. Un enfoque práctico para el clínico. Insuficiencia Cardiaca. 2011;3:131-43.

16. Lipshultz SE, Adams MJ, Colan SD, Constine LS, Herman EH, Hsu DT, et al. Long term cardiovascular toxicity in children, adolescents and Young adults who receive cancer therapy pathophysiology, course, monitoring, management, prevention and research directions: a scientific statement from the American Heart Association. Circulation. 2013;128:1927-95.

17. Van der Pal JH, Van Dijk, Geskus BR, Kok EW, Koolen M, Sieswerda E, et al. Valvular abnormalities detected by echocardiography in 5-year survivors of childhood cancer: a long-term follow-up study. Int J Radiation Oncol Biol Phys. 2015;91:213-22.

18. Tran CJ, Ruble K, Loeb MD, Chen RA, Thompson RW. Automated functional imaging by $2 \mathrm{D}$ speckle tracking Echocardiography reveals high incidence of abnormal longitudinal strain in a cohort of pediatric oncology patients. Pediatr Blood Cancer. 2016;63:1075-80. 
19. Negishi T, Negishi K. Echocardiographic evaluation of cardiac function after cancer chemotherapy. J Echocardiogr. 2018;16:20-7.

20. Pignatelli RH, Ghazi P, Chandra B RS, Thompson P, Cui Q, Castro J. Abnormal myocardial strain indices in children receiving anthracycline chemotherapy. Pediatr Cardiol. 2015;36:1610-6.

21. Narayan V, Ky B. Common cardiovascular complications of cancer therapy: Epidemiology, risk prediction, and prevention. Annu Rev Med. 2018;69:97-111.

22. Plana JC. Chemotherapy and the heart. Rev Esp Cardiol. 2011;64: 409-15.

23. Thavendiranathan P, Poulin F, Lim KD. Use of myocardial strain imaging by echocardiography for the early detection of cardiotoxicity in patients during and after cancer chemotherapy: a systematic review. J Am Coll Cardiol. 2014;63:2751-68.

24. Spewak BM, Williamson SR, Mertens CA, Border LW, Meacham RL, Wasilewski-Masker JK. Yield of screening echocardiograms during pediatric follow-up in survivors treated with anthracyclines and cardiotoxic radiation. Pediatr Blood Cancer. 2017;64(6)

25. Olaya P, Sanchez J, Osorio LF. Strain y strain rate para dummies. Rev Colomb Cardiol. 2011;18:340-4.

26. Ganame J, Mertens L. Quantitative methods in echocardiography-advanced techniques in the assessment of ventricular function. En: Eidem WB Cetta F, O'Leary WP, editores. Echocardiography in pediatric and adult congenital heart disease. Filadelfia: Lipincott Williams \& Wilkinson; 2010. pp. 57-61.
27. Marcus KA, Mavinkurve-Groothuis AMC, Barends M, van Dijk A, Feuth T, de Korte $C$, et al. Reference values for myocardial two-dimensional strain echocardiography in a healthy pediatric and young adult cohort. J Am Soc Echocardiogr. 2011;24:625-36.

28. Poterucha JT, Kutty S, Lindquist RK, Li L, Eidem BW. Changes in left ventricular longitudinal strain with anthracycline chemotherapy in adolescents precede subsequent deceased left ventricular ejection fraction. $\mathrm{J}$ Am Soc Echocardiogr. 2012;25:733-40.

29. Cilsal E, Oguz DA, Tunaoglu SF, Kula S, Pektas A. Subclinical reduction in left ventricular funciton using triplane and 2D speckle tracking echocardiography aftr anthracycline exposure in children. Anatol J Cardiol. 2018:19:58-66.

30. Calabrese V, Menna P, Annibali O, Armento G, Carpino A, Cerchiara E, et al. Early diastolic dysfunction after cancer chemoterapy: Primary endpoint results of a multicenter cardio-oncology study. Chemoterapy. 2018;63:55-63.

31. Wang TJ, Evans JC, Benjamin EJ, Levy D, Le Roy EC, Vasan RS. Natural history of asymptomatic left ventricular systolic dysfunction in the community. Circulation. 2003;108:977-82.

32. López FT, García MA, Beltrán SA, Luis MA, Sanz GR, Ramos MP, et al. Cardio-Onco-Hematología en la práctica clínica. Documento de consenso y recomendaciones. Rev Esp Cardiol. 2017;70:474-86.

33. Loar RW, Noel CV, Tunuguntka $\mathrm{H}$, Colquitt JL, Pignatelli RH. State of the art review: Chemotherapy-induced cardiotoxicity in children. Cong Heart Dis. 2018;13:5-15.

34. Navarrete HS, Castellanos MA, Chaparro SA. Cardiotoxicidad por quimioterápicos. Un enfoque práctico para el clínico. Insuficiencia Cardiaca. 2011;6:131-43. 